Florida International University FIU Digital Commons

11-15-1995

\title{
The hardiness of adult survivors of childhood sexual abuse and their adaptation to a healthy adult life style
}

Myra P. Buttacavoli

Florida International University

DOI: $10.25148 /$ etd.FI14052508

Follow this and additional works at: https://digitalcommons.fiu.edu/etd

Part of the Psychiatric and Mental Health Nursing Commons

\section{Recommended Citation}

Buttacavoli, Myra P., "The hardiness of adult survivors of childhood sexual abuse and their adaptation to a healthy adult life style" (1995). FIU Electronic Theses and Dissertations. 2002.

https://digitalcommons.fiu.edu/etd/2002 


\section{FLORIDA INTERNATIONAL UNIVERSITY}

Miami, Florida

THE HARDINESS OF ADULT SURVIVORS OF CHILDHOOD SEXUAL ABUSE AND THEIR ADAPTATION TO A HEALTHY ADULT LIFESTYLE

A thesis submitted in partial satisfaction of the requirement for the degree of

MASTERS OF SCIENCE

IN

NURSING

by

Myra P. Buttacavoli

1995 
To: Dean Linda Simunek

College of Nursing

This thesis, written by Myra Buttacavoli, and entitled THE HARDINESS OF ADULT

SURVIVORS OF CHILDHOOD SEXUAL ABUSE AND THEIR ADAPTATION TO A

HEALTHY ADULT LIFE STYLE, having been approved in respect to style and intellectual content, is referred to you for judgment.

We have read this thesis and recommended that it be approved.

Joan Levi
Lynúe Hektor
Majiç Hayes Professor

Date of Defense: November 16, 1995

The thesis of Myra Buttacavoli is approved.

Déálínda Simuné

Colligge of Nursing

Dr. Richard L. Campbell

Dean of Graduate studies

Florida International University, 1995 
I dedicate this thesis to my husband Louis, my daughters Eva and Dianne and my son-in-law Kevin, all of whom made this experience positive with their love, support and continuous encouragement. Without them this venture would not have been possible. 


\section{ACKNOWLEDGMENTS}

I wish to thank the members of my committee for their guidance and encouragement. I would also like to thank my fellow students and friends for their support and interest. Most of all I wish to thank the participants of this study as it was very difficult for some to bring forth such sensitive childhood experiences.

A special thanks to my major professor Dr. Janice Hayes, who was instrumental in the completion of this project. 


\title{
ABSTRACT OF THE THESIS
}

THE HARDINESS OF ADULT SURVIVORS OF CHILD SEXUAL ABUSE AND THEIR ADAPTATION TO A HEALTHY ADULT LIFE STYLE

\author{
by \\ Myra Power Buttacavoli \\ Florida International University, 1995 \\ Professor Janice Hayes, Major Professor
}

There are many negative consequences of childhood sexual abuse, (Browne \& Finkelhor, 1990). These effects do not vanish with adulthood and some adults stay scarred for life. However, it has been noted that some victims of childhood sexual abuse recover better than others regardless of the particular type of abuse. Could this adaptation be related to, or represent "hardiness" of the adult?

The purpose of this report is to explore the hardiness of adult victims of child sexual abuse and the adaptation strategies practiced. To achieve this goal, The Health Related Hardiness Scale, created by Susan Pollock, $\mathrm{PhD}$. was adopted. Data was collected from fifteen adult females who, by their own definition were sexually abused as children. They completed the HRHS questionnaire and a demographic questionnaire. Data analysis revealed a significant $p$-value of 0.0002 indicating that support is an important component to "buffer" the negative effects of stress. However this study revealed a high level of hardiness overall in the participating individuals 
I. INTRODUCTION

II. LITERATURE REVIEW 7

Effects of Sexual Abuse 7

Short Term Effects 8

Intrafamilial versus Extrafamilial Abuse Support

Post-Traumatic Stress Disorder

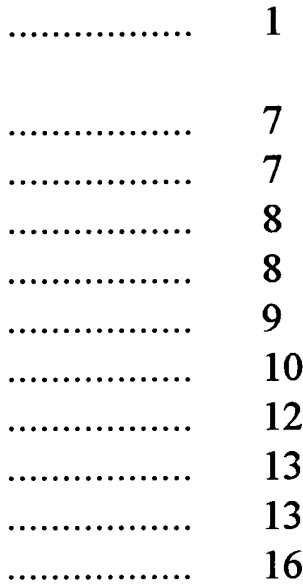

III. METHODOLOGY

Design

Sample

Instrument

Validity \& Reliability

Data Collection

20

Data Analysis

IV. PRESENTATION OF FINDINGS

Characteristics of Findings

V. DISCUSSION OF FINDINGS

Limitations of Study

Recommendations for Future Studies

REFERENCES 


\section{LIST OF TABLES}

TABLE

PAGE

1 Hardiness Score Comparison of

Survivors' Demographic Structure

23

2 Effectof Social Support on Hardiness

24

$3 \quad$ Validity and Reliabilty Analysis

25

4 Component Factor Analysis

27 


\section{LIST OF APPENDICES}

APPENDIX

PAGE

A Informed Consent of Adult Survivors of

Childhood Sexual Abuse

B Health-Related Hardiness Scale

35

C Demographic Data Questionnaire

40

D Graduate Studies Bulletin

41 


\section{CHAPTER I}

\section{INTRODUCTION}

Of all the crimes ever conceived or committed, none inspires more revulsion and disbelief than the sexual abuse of children by adults. The problem of sexual abuse has received considerable attention in the past decade as evidenced by the dramatic increase in the number of journal articles and books related to the topic. Although early literature was predominantly clinical in nature, empirical data has recently emerged, (Kelley, 1991). According to the U.S. Department of Health and Human Services (1982), official estimates of the incidence and prevalence for child sexual abuse barely represents the "tip of the iceberg" of an immense social problem in this country.

There are many negative consequences of childhood sexual abuse including running away, behavior disorders, delinquency, aggressiveness, promiscuity, and inappropriate sexual behavior, (Browne \& Finkelhor, 1986). These conditions do not vanish with adulthood and some adults remain scarred for life. However, it has been noted that some victims of childhood sexual abuse recover better than others regardless of the particular type of abuse. Could this adaptation be related to the "hardiness" of the adult or child?

Human responses to the same stressor or stressful situation vary markedly as do adaptational outcomes (Taylor, 1983). According to Carmen \& Rieker (1989), the victim accommodates to the interplay between the abuse events, family relationships, and other 
life contexts. These accommodations, originally adaptive survival strategies, later form the core of the survivor's psychopathology.

The correlation between hardiness and adaptation to stressful situations such as child abuse is of important clinical concern to nurses and health professionals. This is because of the prevalence of childhood sexual abuse in society and the frequency, severity and diversity of long term effects, (Doob, 1992).

A number of investigations have reported the link between childhood abuse histories and the development of psychiatric symptomatology in adulthood. The lasting effects described in the literature range from disturbances in mood to the development of negative personality characteristics that can lead to violent aggressive behavior that may perpetuate the cycle of abuse (Glod, 1993).

\section{PURPOSE}

The purpose of this inquiry is to explore the hardiness of adult victims of child sexual abuse and their adaptation strategies.

Because the problem of child sexual abuse is of concern to many disciplines including nursing, researchers from diverse backgrounds have begun systematic inquiry into the prevalence, nature, and impact of child sexual abuse (Krugman, 1986). Because the research of child sexual abuse is in an early stage of development there is limited information exploring the long-term effects and how adults have adapted to the stressors of being sexually abused as children. 


\section{GENERAL PROBLEMS}

What are the long term effects of child sexual abuse?

How do sexually abused individuals adapt to the stressors of sexual abuse?

\section{SPECIFIC PROBLEMS}

Does hardiness have an effect on adult victims of childhood sexual abuse?

Do certain individuals, who consider themselves hardy, differ in their perception of stressors?

Do certain sexually abused individuals who are considered to have higher levels of hardiness adapt more favorably to environmental stressors than sexually abused individuals who are considered to have lower levels of hardiness?

\section{OPERATIONAL DEFINITIONS}

Child Sexual Abuse Child sexual abuse can be defined as the engaging of a child in sexual activities that the child does not understand, to which the child cannot give informed consent, or which violate the social taboos of society. This definition is broad and includes intrafamilial and extrafamilial forms and all types of sexual activities (e.g., exhibitionism, fondling, child pornography, oral, anal, and genital sexual contact), (Glod, 1993). In this study, adults over the age of 18 years of age with self reported sexual abuse 
as a child before the age of 18 will be measured for levels of hardiness according to the Health Related Hardiness Scale created by Susan E. Pollack, Ph.D, 1990.

Hardiness Derived from existential personality theory, the hardiness characteristic has been identified as a personality resource that buffers the negative effects of stress. According to Dr. Pollock,s Hardiness Scale comittment and challenge are closely related in the concept of hardiness.

Adaptation Nursing Theorist Sister Callista Roy's model focuses on the concept of adaptation of human (Marriner-Tomey, 1994). Concepts of nursing, person, health, and environment are all interrelated to this central concept. This model has been defined as a theoretical system of knowledge that prescribes a process of analysis and adaptation related to the care of the ill or potentially ill person. Management of environmental stimuli is promoted, including increasing, decreasing, maintaining, removing, altering, or changing for the purpose of being and becoming an integrated and whole person (Fawcett, 1989).

\section{SIGNIFICANCE}

Currently it is estimated that 1.5 million American children yearly experience emotional, physical, and/or sexual abuse and/or neglect (U.S. Department of Health and Human Services, 1988). Such children are at high risk for developing mental disorders later in life (Institute of Medicine, 1989). 
The available research indicates that sexually abused children display a variety of disturbed behaviors in the period of time immediately following disclosure of the abuse. Initial effects of sexual abuse acording to the literature include fear, (Anderson, Bach \& Griffith, 1981) and guilt and shame (Conte \& Schuerman, 1987), (DeFrancis, 1969), (Gomes-Schwartz et al., 1985), anger and hostility (Kelley, 1989).

Interpersonal violence in the form of sexual abuse impacts basic life process, leading to disruption in development, affective stability, interpersonal relationships, cognition, and physical well-being. This represents a human response to the personenvironment interaction, resulting in a disruption of functional health patterns. It has been proposed that maladaptation to this disruption leads to the development of acute symptomatology in childhood and long-term psychiatric sequelae in adults.

Based on her extensive clinical experience, Terr (1991), hypothesized that despite diagnosis of other psychiatric disorders, childhood abuse is associated with four sets of persistent symptomatology in adulthood: visualized or repeatedly perceived memories of trauma, repetitive behaviors, trauma-specific fears, and changed attitudes about people, life and the future. Finklehor (1990), noted that long-term effects of abuse are generally associated with depression, anxiety, self-destructive behavior, isolation, poor self-esteem, trust issues, revictimization, substance abuse, and sexual maladjustment. Preliminary reports began emerging in the 1970s and 1980s which suggested a link between childhood sexual abuse and the development of severe psychopathology in adults. Before 1987, most of the literature consisted of uncontrolled studies that noted the association between 
abuse and the development of various emotional, psychological and behavioral disturbances (DeFrancis, 1969), (Anderson et al., 1981).

Individuals can not only remain healthy under stressful situations but also may benefit if they perceive the events as opportunities for mastery and personal growth (Finklehor, 1990). However, theoretical concerns about the relation of generic hardiness to health, lack of empirical support for the effect of hardiness on adaptation to health problems have limited its relevance to the nursing profession. To overcome these problems, particularly in nursing research, a health related hardiness construct was proposed (Pollock, 1986) that served as the conceptual basis for the Health-Related Hardiness Scale (HRHS) (Pollock, 1990).

Thus, what this study proposes to investigate is the level of hardiness of the participants and the variables that are involved such as adaptation, support, early intervention and long and short term effects. 


\section{CHAPTER II}

\section{LITERATURE REVIEW}

Effects of sexual abuse

Short and long term effects of sexual abuse are reviewed.

This literature shows the relationship between the hardiness of some victims and their ability to adapt more successfully than victims not considered hardy. Hardiness promotes health and adaptation. Therefore, Roy's Adaptation Model (1977) will be discussed emphasizing factors that influence response and the subsequent level of adaptation established in certain adult survivors of child sexual abuse.

There has been some speculation that the older the child is at the time of the abuse incident, the greater the subsequent disturbances (Tsai, Feldman-Summer, \& Edgar, 1979). However, in her recent review of the psychological effects of child sexual abuse, Berliner (1991) noted that age has not been consistently associated with the severity of impact. A number of studies of children and adolescents have reported greater disturbances in children abused during the preteen and teenage years compared to children abused at younger ages (Adams \& Tucker, 1982), (Peters, 1976), (Sedney \& Brooks, 1984), (Sirles, Smith, \& Kusama, 1989). Other studies that examined outcome in adults have reported finding the opposite pattern with abuse at younger ages associated with greater trauma (Courtois, 1979). (Meiselman, 1978), (Russell, 1986). Kinkelhor, (1979) for example, reported a trend for sexual abuse before the age of nine to be associated with long term consequences. In their study of six to sixteen-year-old children, Wolfe and colleagues (1989) also found more severe problems in the younger children. Results from 
a chart review study of adults in treatment (Meiselman, 1978) and a study of a community sample (Courtois, 1979) suggest that prepubertal sexual abuse has more long-term effects than post-pubertal. Other studies with adult victims of childhood sexual abuse have found no relationship between age of onset and severity of outcome (Alexander \& Lupfer, 1987), (Browne \& Finkelhor, 1986), (Finkelhor, 1979).

Short-term effects In their review of the short-term effects of child sexual abuse, Beitchman and colleagues (1991) concluded that present knowledge about the relationship between age of onset and severity of outcome is inconclusive. They provide two possible explanations for the lack of consistency in these findings. First, they suggest that when victims are assessed as children, the full extent of the consequences may not be manifest. As children grow and develop, new symptoms associated with their abuse may emerge. To test this hypothesis, they suggest the need for prospective longitudinal studies. Second, they suggest that the age of onset may be related to the duration of the abuse and type of abuse experience and this might be confounded with outcomes. Young children may not have suffered the abuse for a long period of time and may not have experienced the use of force and threats that may be more common aspects of sexual abuse with older children and adolescents (Gomes-Schwartz et al, 1985), (Peters, 1976).

$\underline{\text { Intrafamilial versus extrafamilial abuse }}$

Some have suggested that children who were sexually victimized by people they knew showed more long-term pathology and appeared to suffer more than children sexually victimized by strangers (Gagnon, 1965). Findings 
from a number of studies found that sexual abuse perpetrated by a biological father (or stepfather) was associated with greater trauma in the victim (Sirles, Smith, \& Kusama, 1989), whereas other studies comparing intrafamilial versus extrafamilial abuse found no differences in degree or type of subsequent symptoms (Friedrich, et al., 1986). It has also been suggested that the consequences of childhood sexual abuse may be a function of the severity of the abuse, with incidents involving penetration assumed to be associated with more mental health problems or more severe sequelae (Mannarino \& Cohen, 1987), in comparison to incidents without penetration.

Support Researchers have recently begun to acknowledge that studies of the impact of childhood sexual abuse find substantial groups of individuals who appear to have little or no symptomatology (Sirles, Smith, \& Kusama, 1989). There are a number of possible explanations to these findings, including inadequate measurement techniques or denial on the part of the victims. It is also possible that some factors or characteristics of the abuse incident (less severe) or characteristics of the child (good coping skills) or the child's environment (a relationship with a significant and supportive person) may have acted to buffer the individual from long-term consequences.

While early research documented the serious consequences associated with childhood victimization, and some have suggested clinical factors that distinguish abused youths who become violent adults and those who do not (Lewis, 1992), future research needs to examine cases where children appear to have overcome, or been protected from, negative consequences of their early childhood experiences. Such knowledge would have 
important implications for the development of prevention and treatment programs for children who experience early childhood sexual abuse.

Post Traumatic Stress Disorder Several investigators have reported the link between childhood physical and sexual abuse and the subsequent development of posttraumatic stress disorder (PTSD) (Gelinas, 1983), (Goodwin 1985). Despite the link between childhood physical and sexual abuse and the subsequent development of PTSD, some studies suggest that not all victims of childhood abuse show symptoms of this disorder. Finklehor (1990) reported that although a significant fraction of abuse victims will develop symptoms of PTSD, abuse often lacks the violent circumstances associated with other traumas (combat, kidnapping, etc.). He refers to abuse as a "situation, relationship, or process" that leads to a whole host of detrimental consequences (Finklehor, 1990). This suggests that whereas PTSD may be one possible outcome of childhood sexual abuse, other factors such as duration of abuse, age of onset, violence involved, and perpetrator to name a few, may be other important determinants of long-term sequelae. Alternative studies of abused children suggest that whereas up to 55\% may develop PTSD, others may be more likely to develop symptoms of anxiety, depression, and externalizing behaviors (Riser, Heston, Millsap, \& Pruitt, 1991). The notion of PTSD does not apply to all forms of sexual abuse or all abusive experiences. Further research is necessary to sort out the relative importance of this factor, especially in relation to various developmental trajectories. 
Implications for clinical assessment and treatment may be drawn from these findings. The psychological impact of sexual abuse may be disguised by the child's developmental level, as well as by the fact that most children cannot report their psychological reactions to trauma unless they are asked specifically about aspects of the trauma. Some children moreover, appear to be less affected by such events, which could be related to the child's appraisal of the situation (e.g., absence of threat cues), real and perceived availability of coping resources (e.g., supportive family members, rapid and effective deterrence), the interaction between severity of abuse and developmental level, or failure to detect subtle signs of disturbance. Accordingly, treatment directions may be influenced by the extent to which these PTSD-related symptoms are present (Sgroi, 1989). Carmen (et al. 1984), stated that although the psychosocial consequence of abuse are known, the process whereby a victim becomes a patient has not been appreciated by clinicians or adequately conceptualized by researchers of victimization. They developed a psychosocial model of the victim-to-patient process to explain how chronic abuse damages the self and set into motion psychological processes that may evolve into various forms of mental illness (Carmen \& Rieker, 1989). According to Carmen \& Rieker (1989), the victim accommodates to the interplay between the abuse events, family relationships, and other life contexts. These accommodations originally adaptive survival strategies, later form the core of the survivor's psychopathology. After abuse occurs, the victim must accommodate to the judgments of others about the abuse. This accommodation takes the form of denying the occurrence of the abuse, and denying the importance of the abuse by discomfirmation and transformation, (Doob, 1992). 
Several theories of victimization outline the process survivors of trauma experience during recovery. Taylor (1983), for example, identifies three themes, or cognitive tasks, employed by individuals adjusting to threatening events. These tasks are "a search for meaning in the experience, an attempt to regain mastery over the event in particular and over life more generally, and an effort to enhance self-esteem to feel good about oneself again despite the personal setback."

Adaptation Adaptation is a complex process involving numerous internal and external factors that influence response and the subsequent level of adaptation established. The hardiness characteristic has been identified by Dr. Susan Pollock as a motivating factor in resolving stressful situations and in adapting to actual health problems.

Variability in adaptation can be attributed to differences in any of the three stimuli. The residual stimuli were the focus of study to identify internal factors that mediated the stress response and promoted adaptation. Kobasa, (1979) proposed that variability in adaptation to stress was related to generalized resistance resources. From an existentialist point of view, Kobasa identified those resources as hardiness the personality characteristic that enabled individuals to remain healthy even when confronted with stressful life events or a stressful environment. The hardy person was someone who recognized that life required him or her to use judgment (and make good judgment), to make good decisions (control), to become actively involved with others in various activities of life (commitment), and to perceive change as ultimately beneficial to personal development (challenge), (Kobasa, 1979). 
The Healing Process The treatment of adult survivors is an important clinical concern to nurses and mental health professionals because of the prevalence of childhood sexual abuse in society and the frequency, severity and diversity of long term effects. Once they have connected their present experiences to the abuse and allowed themselves to appreciate the impact of the abuse on their lives, many participants described making an active and conscious decision to devote their time and energy to recover from their abuse (Draucker, 1992).

When discussing the healing process of sexual abuse participants of a study by Draucker, (1992), described it as an active, on-going, complex and time-consuming experience involving "hard work." The tasks of healing were often described with terms that implied accepting a challenge, e.g., facing, confronting; working to overcome odds encountered in the environment, e.g., digging away, struggling against, overcoming and building something new, e.g., creating, designing. The metaphor of construction reflects the hard work of healing and captures its active, rather than passive, and constructive rather than destructive elements.

Survivors often experience intense emotions such as anxiety and sadness, in response to making the connection between their present experiences and the abuse. One survivor spoke of someone "pulling the cork," while another stated that the experience was like "opening the floodgates." However, many also described the experience as freeing because they could begin to give meaning to their current problems.

Commitment, Control and Challenge In order to understand why some people are more resistant to the deleterious effects of stress, Kobasa (1979) examined extensively three 
personality characteristics: commitment, control and challenge. Together, they comprise a personality style that resists stress and is considered "hardy." The evolution of the concept of hardiness is based on the work of personality and social psychologists who observed that individuals differ in their perception of environmental stressors. Specifically, an individual's orientation towards life or characteristic interests and motivation are considered an important factor in determining the impact of a given stressful life event. Hardiness has been defined as "a constellation of personality characteristics that function as a resistance resource in the encounter with stressful life events" (Kobasa, Maddi, \& Kahn, 1982).

The utility of hardiness as a mediator in an individual's response to stressful events has been supported in several studies. In a few studies, hardiness has been found to prevent illness in groups of employees who were exposed to high levels of stress (Kobasa 1979), (Kobasa, Maddi, \& Courington, 1981).

It is thought that the indirect effects of hardiness occur when there is a decrease in the use of ineffective or regressive coping strategies. In a study of lawyers, Kobasa (1982) noted that complaints of stress symptomatology were mediated by the personality trait of commitment as well as by the use of regressive coping strategies. Rhodewalt and Agustsdottir (1984) reported that hardy individuals do not experience life events that are qualitatively different from those experienced by non-hardy individuals, but they are more likely to perceive the events they do as positive and under their complete control.

Finkelhor, Hotaling, Lewis \& Smith (1989) hypothesized that child sexual abuse serves as a generalized stressor in adulthood which enhances the probability of 
maladaptive reactions to other stressful or traumatic situations. Thus interventions designed to assist victims of childhood sexual abuse in dealing with their experiences also may increase their ability to cope with other stressful events. It was found that women sexually abused in childhood, who used avoidant/emotion-suppressing strategies to cope with the experience reported poorer psychological adjustment in adulthood. This finding suggests that assisting the women to explore and develop alternative ways of coping with the experience may reduce their psychological distress. Thus, if mediators can be identified, they may serve as targets for interventions (Leitenberg, Greenwald \& Cado 1992).

Childhood sexual abuse has been associated with the development of severe disruption in personality development. Nurses are the most likely health professionals to have contact with these children and their mothers, contact that may occur in a variety of community and clinical settings. Thus, nurses can have a significant impact on the well being of this at risk population through early identification of health needs, as well as preventive and therapeutic interventions. 


\section{THEORETICAL FRAMEWORK}

According to Roy's model of adaptation, as an open and living system the person receives inputs or stimuli from both the environment and the self. The adaptation level is determined by the combined effect of the focal, contextual, and residual stimuli. Adaptation occurs when the person responds positively to environmental changes. This adaptive response promotes the integrity of the person, which leads to health. Ineffective responses to stimuli leads to disruption of the integrity of the person.

There are two interrelated subsystems in Roy's model. The primary, functional, or control processes subsystem consists of the regulator and cognator. The secondary, effector subsystem consists of four adaptive modes: physiological needs, self-concept, role-function, and interdependence.

Roy views the regulator and cognator as methods of coping. Perception of the person links the regulator with the cognator in that "input into the regulator is transformed into perceptions. Perception is a form of the cognator. The responses following perception are feedback into both the cognator and the regulator" (Roy, et al 1977). The four adaptive models of the second subsystem in Roy's model provide form or manifestations of cognator and regular activity. Responses to stimuli are carried out through these four modes. The mode's purpose is to achieve physiological, psychological, and social integrity. Interrelated propositions of the cognator and regulator subsystems link the systems of the adaptive modes.

Human as a whole is made up of six subsystems. These subsystems, the regulator, cognator, and four adaptive modes, are interrelated to form a complex system for the 
purpose of adaptation. Relationships between the four adaptive modes occur when internal and external stimuli affect more than one mode or when one mode becomes the focal, or residual stimulus for another mode.

This is a theory because it includes a goal that is specified as the aim for activity and prescription for activities to realize that goal. The goal of the model is the person's adaptation in four adaptive modes in situations of health and illness. The prescriptions or interventions are the management of stimuli by removing, increasing, decreasing, or altering them. These prescriptions can be obtained by listing practice-related hypotheses generated by the model.

According to Roy's model of adaptation, as an open and living system the person receives inputs or stimuli from both the environment and the self. Ineffective responses to stimuli leads to disruption of the integrity of the person. However, adaptation is considered effective if it promotes the physiological, psychological, and social well-being. Adult victims must generally embark on a long and painful journey to rediscover themselves, their self esteem and self worth. They can, with the constructs of hardiness and support of caregivers, adapt to the stressors associated with sexual abuse.

\section{HYPOTHESIS}

Victims of childhood sexual abuse adapt to stressors related to the sexual abuse based on the level of their hardiness. 


\section{RESEARCH QUESTIONS}

What are the long term effects of child sexual abuse?

Do certain individuals who consider themselves hardy differ in their perception of stressors?

Are victims of childhood sexual abuse who adapt to stressors, considered more hardy than other victims? 


\section{CHAPTER III}

\section{METHODOLOGY}

Design This study measured levels of hardiness of adult survivors of childhood sexual abuse according to the Health Related Hardiness Scale, created by Susan Pollock, Ph.D, (1990). A nonrandomized convenience sample of 15 survivors of childhood sexual abuse was collected. The population was comprised of adult females.

Sample A nonrandomized convenience sample was selected for this study according to the following criteria:

1. Adults over the age of 18 years.

2. Participants have self-reported sexual abuse as a child by definition of sexual abuse.

3. All participants are able to speak, read and understand English.

4. Participants have agreed to this study through informed consent.

Subject recruitment involved referral by counselors and acquaintances of the researcher in South Florida.

Instrument The instrument that was chosen for this study is the Health Related Hardiness Scale (HRHS), created by Susan E Pollock, Ph.D, 1990. This scale consists of 34 questions related to one's perception of health. These questions are presented on a six- 
point Likert scale. Depending on the purpose of the investigation, the scale can be used to measure the unitary construct of health related hardiness and/or the two dimensions of commitment/challenge (20 items) or control (14 items).

Scores for the total HRHS range from 34 to 204 with high scores indicating presence of hardiness. Negatively worded items are indicated by an asterisk; scoring for these items need to be reversed.

A general demographic data questionnaire was used to identify basic information that could influence variables such as social support or lack of support.

Validity Content validity of Dr. Pollock's tool has been established with nursing professionals. Stability of this scale and its discriminant and predictive validity among persons with actual or potential health problems continues to be tested.

Reliability Derived from existential personality theory, the hardiness characteristic has been identified as a personality resource that buffers the negative effects of stress. Kobasa (1979) first introduced the hardiness characteristic as a personality construct that moderates stress-illness.

Pollock (1990) then developed the HRHS which has been repeatedly tested in nursing research. 
Data Collection Permission was obtained from Dr. Susan Pollock and from Florida

International University, I.R.B. Subjects were then recruited by referrals from social workers, psychologists, counselors and self-referrals.

Sample selected was functional adult survivors. Participants were then mailed and/or were given, either by the investigator or a contact person, 1.) an information summary, explaining the study and assuring confidentiality, 2.) a demographic data questionnaire, 3.) a Health Related Hardiness questionnaire, and 4.) an informed consent form.

The completed questionnaires were returned to the investigator's home address in the self-addressed, stamped envelope provided by the investigator. Names were not required on either questionnaire. Questionnaires were assigned a code number to protect each participants' privacy. Envelopes with return addresses will be destroyed.

Data Analysis A simple frequency analysis was performed on the responses. Data was then analyzed to investigate factors on the participant's ability to effectively cope with adult lifestyles after such a childhood encounter of sexual abuse. Support was found to be a significant factor. Total scores obtainable on this scale ranged from 34 to 204 . We divided this score range into three classifications, namely, between 34 and 94 were classified as Low Level of Hardiness, between 95 and 154 as Moderate Level of Hardiness and between 155 and 204 as High Level of Hardiness. Since Dr. Pollock suggested that the questionnaire be grouped into three parts, namely, CONTROL, COMMITMENT and CHALLENGE, we discussed the findings of such analyses. For this, the Principal Factor analytical method was used. It then became apparent that the 
majority of the participants exhibited a high level of hardiness. Therefore it was necessary to conduct further analysis of establishing reliability and validity for this particular group. For this, a Cronbach's alpha was conducted specific to this group

13 of the 15 participants had support of family and/or friends and exhibited high levels of hardiness than the two participants without support. Therefore a two-tail test was performed on the hypothesis that social support has some effect on hardiness.

The table of the non-parametric ANOVA statistic computed a p-value. If the pvalue is less than $\boldsymbol{a} / \mathbf{2}=\mathbf{0 . 0 2 5}$ it can be concluded that the effect of social suppport on hardiness is significant. 


\section{CHAPTER IV}

\section{PRESENTATION OF FINDINGS}

2.1) Demographic Analyses Included is the score and the classification of the

Hardiness scale and its descriptive statistics in the table below in order to better understand the survivors' background.

\section{TABLE 2.1: HARDINESS SCORE COMPARISON OF SURVIVORS'}

\section{DEMOGRAPHIC STRUCTURE}

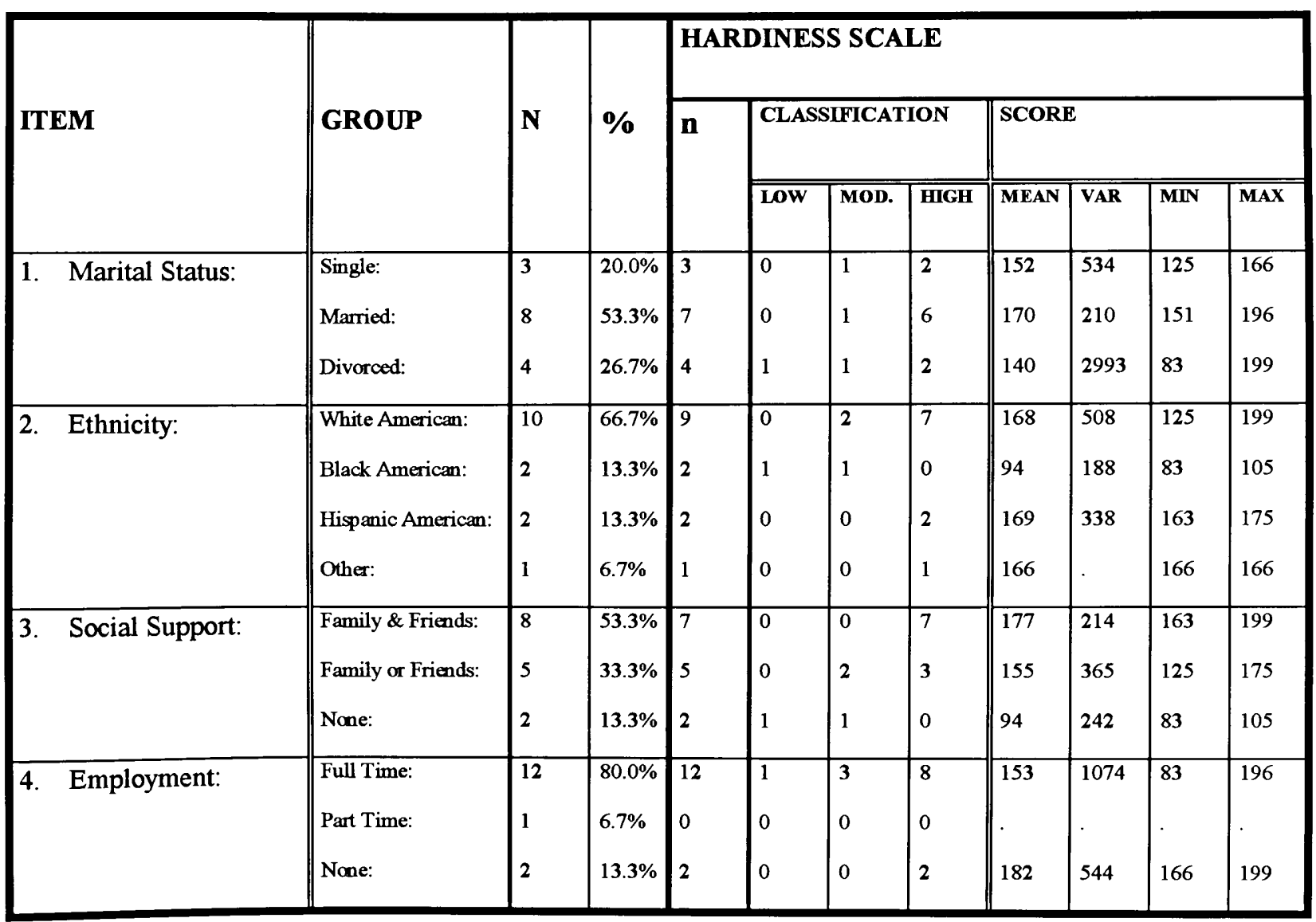


From the table above and an analysis of marital status and social support, it was found that the two people who did not have any social support were Black Americans, divorced and not experiencing high level of hardiness. It was also found that married women seemed to experience a higher level of hardiness. It was also found that married women seemed to experience a higher level of hardiness and enjoy higher social support. Note that if the hardiness scale had been classified a little bit differently, a different conclusion would have occured. For instance, if 150 to 204 had been chosen as the high level of hardiness, then all the married women would have attained high status.

2.2) Significance Test of Social Support: From the table above, it appears that social support seemed to be helpful in order to buffer the negative effects of stress, and below is the result of the non-parametric ANOVA. Recall the level of confidence $\mathbf{1}-\mathbf{a} / \mathbf{2}=\mathbf{0 . 9 7 5}$.

TABLE 2.2: EFFECT OF SOCIAL SUPPORT ON HARDINESS

\begin{tabular}{|l|l|l|l|l|}
\hline SOCIAL SUPPORT & N & MEAN & F-VALUE & P-VALUE \\
\hline Family \& Friends: & 7 & 177 & 19.938 & 0.0002 \\
Family or Friends: & 5 & 155 & & \\
None: & 2 & 94 & & \\
\hline
\end{tabular}

The p-value in the above table shows that social support is indeed a significant factor in dealing with negative effects of negative experiences. The p-value of 0.0002 is less than $\mathbf{a} / 2=0.025$. 
2.3) Validity And Reliability Analyses: The reliability coefficient alpha on the level of hardiness was found to be $\alpha=\mathbf{0 . 9 8}$. That is, this tool, in general, was $98 \%$ reliable. See the attached table of Correlation and Cronbach's Alpha. 


\section{CHAPTER V}

\section{DISCUSSION OF FINDINGS, IMPLICATIONS, LIMITATIONS,}

\section{AND RECOMMENDATIONS}

3.1) Component Factor Analysis This type of analysis is simply trying to group "similar" questions/items together. Dr. Pollock had identified three groups, Control, Commitment and Challenge. She further stated that Commitment and Challenge are closer than they are different. Therefore, this questionnaire was subjected to component factor analysis to see if the survivors saw the same grouping as Dr. Pollock. The results of the analyses shown in Appendix I did not exhibit the same groupings. This is simply because of the small sample of $\mathrm{N}=15$ and Dr. Pollock used $\mathrm{N}=389$. Therefore, her grouping should be more reliable.

When the responses were subjected to further analyses, namely non-parametric ANOVA, social support was still very significant. Because we have such a small sample interpreting our results based on Dr. Pollock's scale, groupings could be misleading.

The very high Cronbach's alpha that was achieved, even though from a very small sample compared to Dr. Pollock's, is still interpretable as being reliable and valid. On a large sample, Dr. Pollock's group achieved between 0.87 and 0.91 . If there was a large sample, it is possible that such a high alpha would not have been acheived, but high enough for the tool to be valid for our group. Note that if the hardiness scale had been classified a little differently, a different conclusion would have occurred. For instance, if 150 to 204 had been chosen as the high level of hardiness, then all the married women 
would have attained high status. Therefore it is evident by analysis, that victims of childhood sexual abuse do adapt to stressors related to the sexual abuse based on the level of their hardiness. The majority of the sample exhibited high levels of hardiness, and support being a significant factor related to the levels of hardiness.

It should be pointed out that subject number seven's scores were not included in the computation because she did not respond to question \#25. But in order to construct the attached table, a score of zero was assigned.

Limitations of Study Small sample size is indeed a limitation of this study. The type of abuse, whether it was a known or unknown abuser and the age of the child when the abuse took place, would all have been beneficial to this study. It was of significant importance to this investigator, however, to not embarrass or make a participant uncomfortable, therefore it was important to keep this study as non-threatening as possible.

\section{$\underline{\text { Recommendations }}$}

1. It has been demonstrated that social support helps the victims of childhood sexual abuse adjust to healthy adult lifestyle, hence this social support system should enhanced and strongly encouraged.

2. The next study should contain more demographic items so that more factors could be available for analyses on their effects on hardiness. 
For researchers as well as clinicians, there appears to be a fairly widespread acceptance of some association between child sexual abuse and later delinquent and criminal consequences. It is interesting to note in this study that most of the participants have high degrees of hardiness. However, support from family and friends seems to be a key factor in the management of stressors. This could very possibly have some impact on the treatment of these victims. It should also be strongly stressed that the nursing profession must be aware of the increasing numbers of sexually abused children and if early intervention is implemented, with minimal trauma, and continued support, these children will indeed grow up to be healthy adults with high degrees of hardiness. 


\section{REFERENCES}

Adams-Tucker, C. (1982). Proximate effects of sexual abuse in childhood: A report on 28 children. American Journal of Psychiatry, 139, 1252-1256.

Alexander, PEC., and Supfer, SEL. (1987). Family characteristics and long-term consequences associated with sexual abuse. Archives of Sexual Behavior, 16, 235235.

Anderson, SUC., Bach, and Griffith, S. (1981). Psychological sequelae in intrafamilil victims of sexual assault and abuse. Paper presented at the Third International Conference on Child Abuse and Neglect, Amsterdam, The Netherlands.

Beitchman, J. H., Zucker, K.J., Hood, J.E., Da Costa, G.A., and Akman, D.(1991). A review of the short-term effects of child sexual abuse. Child Abuse and Neglect.

Berliner, L. (1991). Effects of sexual abuse on children. Violence Update 1. 8, 10-11.

Blue, C. L., Brukaker, K. M., Fine, J. M., Kirsch, M. J., Papazian, K. R. Riestcr, C. M., Labiech, MEA., Sister Callista Roy, Nursing Theorists and Their Work. MarrinerTomey, A. Author. Mosley, St. Louis.

Brown, A., and Finkelhar, D. (1986). Impact of sexual abuse: A review of the research. Psychological Bulletin, 66-77.

Carmen, E. H., Rieker, P. P., and Mills, T. (1984). Victims of violence and psychiatric illness American Journal of Psychiatry, 141, 378-383.

Carmen, E. H., Rieker, P. P. (1989). A psychological model of the victim-to-patient process. Psychiatric Clinics of North America, 12, 431-443.

Conte, J., and Schuerman, J. (1987). The effects of sexual abuse on children. A multidimensional view. Journal of Interpersonal Violence 2, 380-390.

Courtois, C. (1979). The incest experience and its aftermath. Victimology, 337-347. 
DeFrancis, V. (1969). Protecting the child victim of sex crimes committed by adults Denver: American Humane Association.

Doob, D. (1992). Female Sexual Abuse Survivors as Patients: Avoiding Retraumatization. Archives of Psychiatric Nursing. 6.4.245-251.

Draucker, C. B., (1992). The healing process of female adult incest survivors constructing a personal residence. Image Journal of Nursing Scholarship 24.1, 4-

Fawcett, J. (1989). Analysis and Evaluation of Nursing Theories. Philadelphia. 17.A. Davis.

Finkelhor, D. (1979). Sexually Victimized Children. New York: Free Press.

Finkelhor, D. (1990). Early and long-term effects of child .sexual abuse: An update. Professional Psychology: Research and Practice, 21, 325-330.

Finkelhor, D., Hotaling, GHT., Lewis, I. A., and Smith, C. (1989). Sexual Abuse and its relationship to later sexual satisfaction, marital status, religion, and attitudes. Journal of Interpersonal Violence, 4, 379-399.

Fliedlich, W., N., Urquiza, A. J., and Beilker, R. L., (1986). Behavior problems in sexually abused young children. Journal of Pediatric Psychology, 1 1, 47-57.

Gagnon, J. (1965). Female child victims of sex offenses. Social Problems, 13, 176- 192.

Gelinas, D. (1983). The persisting negative effects of incest. Psychiatry, 46, 312-322.

Glod, Carol A. (1993). Long-term Consequences of childhood physical and sexual abuse. Archives of Psychiatric Nursing. 7.3. 163-173.

Goms-Schwartz, B., Horowitz, J., and Sauzier, M. (1985). Severity of emotional distress among sexually abused pre-school, school-age and adolescent children. Hospital and Community Psychiatry, 36. 503-508.

Goodwin, J. (1985). Post-traumatic stress in incest victims. In S. E and RES. Pyroos (eds.), Post traumatic stress disorder in children. Washington, D.C., American Psychiatric Association.

Institute of Medicine (1989). Research on children and adolescents with mental, behavioral and developmental disorders. Washington, D.C. National Academy Press. 
Kelley, Susan J. (1991). Methodological issues in child sexual abuse research. Journal of Pediatric Nursing. 6.1. 21-28.

Kieser, L. J., Heston, J., Milsap, P. A. and Pruitt, D. B., (1991). Physical and sexual abuse in childhood: Relationship with postatraumatic stress disorder. Journal of the American Academy of Child and Adolescent Psychiatry. 30. 776-783.

Kobasa, S. C. (1979). Stressful life events, personality and health: An inquiry into hardiness. Journal of Personal Social Psychology. 1979 37. 1.1 -11.

Kobasa, S. C. (1982). Commitment and coping in stress resistance among lawyers. Journal of Personality and Social Psychology, 42, 707-717.

Kobasa, S. C., Maddie, S. R., and Courington, S. (1981). Personality and constitution as mediations in their stress-illness relationship. Journal of Health and Social Behavior, 22, 368-378.

Krugman, Richard, (1986). Recognition of sexual abuse in children. Pediatrics in Review. 8.1. 25-30.

Lewis, D. O. (1992). From abuse to violence: Psychological consequences of maltreatment. Journal of the American Academy of Child and Adolescent Psychiatry, 31, 383-391.

Manacino, A., and Cohen, J. (1987). Psychological symptoms of sexually abused children. Paper presented at the Third National Family Violence Conference. Durham, N. H.

Meiselman, K, (1978). Incest. San Francisco, CA: Jassey-Bass.

Peters, J. J., (1976). Children who are victims of sexual assault and the psychology of offenders. American Journal of Psychotherapy, 30. 398-421.

Pollock, Susan E., 1989. The hardiness characteristic: A motivating factor in adaptation. Advances in Nursing Science v. 12. 53-62.

Rhodewalt, F., and Agustsdottin, S. (1984). On the relationship of hardiness to the. Type A behavior pattern: Perception of life events versus coping with life events. Journal of Research in Personality, 18. 212-223.

Roy, C. (1976). The Roy adaptation model: Comment. Nursing Outlook, 24: 690-691.

Russell, D. E. H. (1986). The secret trauma: incest in the lives of girls and women. New York: Basic Books. 
Sardis, J. (1956). Experiences of 500 children and adult sexual deviation Quarterly New York, Supplement, 30, 92-109.

Sedrey, M. A. and Brooks, B. (1984). Factors associated with a history of childhood sexual experience in a non-clinical female population. Journal of the American Academy of Child Psychiatry, 23, 215-218.

Sgroi, S. M. (1989). Vulnerable populations: Sexual abuse treatment for children, adult survivors and persons with mental retardation (Vol. 2). Lexington, MA: Lexington Books

Sirles, E. A., Smith, J. A., and Kusama, H. (1989). Psychiatric status of intrafamilial child sexual abuse victims. Journal of the American Academy of Child and Adolescent Psychiatry, 23, 225-229.

Sitenberg, H., Greenwald, E., and Cado, S. (1992). A retrospective study of long term methods of coping with having been sexually abused during childhood. Child Abuse and Neglect, 16, 399-407.

Terr, L. C. (1991). Childhood traumas: An outline and overview. American Journal of Psychiatry, 148, 10-20.

Tsai, M., Feldman-Summers, S., and Edgar M (1979). Childhood molestation Variables related to differential impact of psycho sexual functioning in adult women Journal of Abnormal Psychology, 88. 407-417.

U. S. Department of Health and Human Services. 1982. Executive summary: National study of the incidence and severity of child abuse and neglect. Washington, D.C.

Widom, C. S. (1991). Childhood victimization: Risk factor for delinquency. In M.D. Colven, and S. Gore (Eds.). Adolescent stress: Causes and consequences 201-221. New York: Aldine de Gruyter. 


\section{INFORMED CONSENT FORM}

PROJECT TITLE:

The Hardiness of Survivors of Childhood Sexual Abuse and Their Adaptation to a Healthy Adult Life Style.

I freely and voluntarily consent to be a participant in the research project entitled, The Hardiness of Survivors of Childhood Sexual Abuse and Their Adaptation to a Healthy Adult Life Style, to be conducted at Florida International University during the Summer semester, 1995, with Myra Buttacavoli as Principle Investigator. I have been told that this project will last approximately 20 minutes.

I understand that the purpose of this research is to compare and analyze the short and long term effects of the hardiness of childhood sexual abuse in adaptation to a healthy adult life style. There are approximately 15-20 participants in this study.

I understand that there are no known risks or benefits involved in my participation in this project. I have been told that my responses will be kept strictly confidential. All scores will be identified only by a code number, and my individual participation will not be revealed to anyone.

I understand that I may withdraw my consent and discontinue participation in this research project at any time without negative consequences. I have been given the right to ask questions concerning the procedure, and any questions have been answered to my satisfaction.

I understand that if I desire further information about this research, I should contact Principal Investigator Myra Buttacavoli at (305) 662-8343 Extension 4104. I have been offered a copy of this informed consent form.

I have read and understand the above.

Participant's signature

Date

I have explained and defined in detail the research procedure in which the participant has agreed to participate, and have offered him/her a copy of this consent form.

Principal Investigator's signature

Date 
Instructions:

This is a questionnaire designed to determine the way in which different people view certain important issues related to their health. Each item is a belief statement with which you may agree or disagree. Beside each statement is a scale which ranges from strongly disagree (1) to strongly agree (6). For each item we would like you to circle the number that represents the extent to which you disagree or agree with the statement. Please make sure that you answer every item and that you circle only one number per item. Thank you for taking the time to complete this questionnaire.

DISAGREE

$\begin{array}{ccc}\text { DISAGREE } & \\ & & \\ \text { S } & \text { M } & \text { S } \\ \text { T } & \text { O } & \text { L } \\ \text { R } & \text { D } & \text { I } \\ \text { O } & \text { E } & \text { G } \\ \text { N } & \text { R } & \text { H } \\ \text { G } & \text { A } & \text { T } \\ \text { L } & \text { T } & \text { L } \\ \text { Y } & \text { E } & \text { Y } \\ & \text { L } & \\ & \text { Y } & \end{array}$

AGREE

S $\quad$ M S

L $\quad$ O $\quad$ T

I $\quad \mathbf{D} \quad \mathbf{R}$

G E $\quad$ O

$\begin{array}{lll}\mathbf{H} & \mathrm{R} & \mathrm{N}\end{array}$

T $\quad$ A $\quad$ G

$\begin{array}{lll}\text { L } & \text { T } & \text { L }\end{array}$

Y E $\quad$ Y

L

Y

1. Involvement in health promotion activities is stimulating.

$$
\begin{array}{llllll}
1 & 2 & 3 & 4 & 5 & 6
\end{array}
$$

2. I can avoid illness if I take care of myself.
1
23
45
6

3. I find it difficult to be enthusiastic about good health.
1
2
3 


$\begin{array}{llllll}\text { S } & \text { M } & \text { S } & \text { S } & \text { M } & \text { S } \\ \text { T } & \text { O } & \text { L } & \text { L } & \text { O } & \text { T } \\ \text { R } & \text { D } & \text { I } & \text { I } & \text { D } & \text { R } \\ \text { O } & \text { E } & \text { G } & \text { G } & \text { E } & \text { O } \\ \text { N } & \text { R } & \text { H } & \text { H } & \text { R } & \text { N } \\ \text { G } & \text { A } & \text { T } & \text { T } & \text { A } & \text { G } \\ \text { L } & \text { T } & \text { L } & \text { L } & \text { T } & \text { L } \\ \text { Y } & \text { E } & \text { Y } & \text { Y } & \text { E } & \text { Y } \\ & \text { L } & & & \text { L } & \\ & \text { Y } & & & \text { Y } & \end{array}$

4. Luck plays a big part in determining how soon I will recover from an illness.

$$
\begin{array}{llllll}
1 & 2 & 3 & 4 & 5 & 6
\end{array}
$$

5. No matter how hard I try to maintain my health, my efforts will accomplish very little.

$$
\begin{array}{lll}
1 & 2 & 3
\end{array}
$$$$
4
$$$$
5
$$$$
6
$$

6. I am in control of my health.

$$
\begin{array}{llllll}
1 & 2 & 3 & 4 & 5 & 6
\end{array}
$$

7. I admire people who work hard to improve their health.

$$
\begin{array}{llllll}
1 & 2 & 3 & 4 & 5 & 6
\end{array}
$$

8. Good health is more important to me than financial security.

$$
\begin{array}{lllllll}
1 & 2 & 3 & 4 & 5 & 6
\end{array}
$$

9. My good health is largely a matter of good fortune.

$$
\begin{array}{llllll}
1 & 2 & 3 & 4 & 5 & 6
\end{array}
$$

10. No matter what I do, I'm likely to get sick.

$$
\begin{array}{llllll}
1 & 2 & 3 & 4 & 5 & 6
\end{array}
$$

11. I find it boring to eat and exercise properly to maintain my health.

$$
\begin{array}{llllll}
1 & 2 & 3 & 4 & 5 & 6
\end{array}
$$

12. The main thing which affects my health is what I myself do.

$$
\begin{array}{llllll}
1 & 2 & 3 & 4 & 5 & 6
\end{array}
$$

13. Changes taking place in health care are not exciting to me.

$$
\begin{array}{llll}
1 & 2 & 3 & 4
\end{array}
$$




$\begin{array}{llllll}\text { S } & \text { M } & \text { S } & \text { S } & \text { M } & \text { S } \\ \text { T } & \text { O } & \text { L } & \text { L } & \text { O } & \text { T } \\ \text { R } & \text { D } & \text { I } & \text { I } & \text { D } & \text { R } \\ \text { O } & \text { E } & \text { G } & \text { G } & \text { E } & \text { O } \\ \text { N } & \text { R } & \text { H } & \text { H } & \text { R } & \text { N } \\ \text { G } & \text { A } & \text { T } & \text { T } & \text { A } & \text { G } \\ \text { L } & \text { T } & \text { L } & \text { L } & \text { T } & \text { L } \\ \text { Y } & \text { E } & \text { Y } & \text { Y } & \text { E } & \text { Y } \\ & \text { L } & & & \text { L } & \\ & \text { Y } & & & \text { Y } & \end{array}$

14. I find people who are involved in health promotion interesting

$$
\begin{array}{lllllll}
1 & 2 & 3 & 4 & 5 & 6
\end{array}
$$

15. Setting goals for health is unrealistic.

$$
\begin{array}{lllllll}
1 & 2 & 3 & 4 & 5 & 6
\end{array}
$$

16. Most things that affect my health happen to me by accident.

$$
\begin{array}{llllll}
1 & 2 & 3 & 4 & 5 & 6
\end{array}
$$

17. Changes taking place in health care will have no effect on me.

$$
\begin{array}{llllll}
1 & 2 & 3 & 4 & 5 & 6
\end{array}
$$

18. If I get sick, it is my own behavior that determines how soon I get well.

$$
\begin{array}{llllll}
1 & 2 & 3 & 4 & 5 & 6
\end{array}
$$

19. I do not find it interesting to learn about health.

$$
\begin{array}{lllllll}
1 & 2 & 3 & 4 & 5 & 6
\end{array}
$$

20. I will stay healthy if it's meant to be.

$$
\begin{array}{llllll}
1 & 2 & 3 & 4 & 5 & 6
\end{array}
$$

21. I am not interested in exploring new ways to improve my health.

$$
\begin{array}{llllll}
1 & 2 & 3 & 4 & 5 & 6
\end{array}
$$

22. No matter what I do, if I am going to get sick, I will get sick.

$$
\begin{array}{llllll}
1 & 2 & 3 & 4 & 5 & 6
\end{array}
$$

23. I feel no need to try to maintain my health because it makes no difference anyway. 


$\begin{array}{llllll}\text { S } & \text { M } & \text { S } & \text { S } & \text { M } & \text { S } \\ \text { T } & \text { O } & \text { L } & \text { L } & \text { O } & \text { T } \\ \text { R } & \text { D } & \text { I } & \text { I } & \text { D } & \text { R } \\ \text { O } & \text { E } & \text { G } & \text { G } & \text { E } & \text { O } \\ \text { N } & \text { R } & \text { H } & \text { H } & \text { R } & \text { N } \\ \text { G } & \text { A } & \text { T } & \text { T } & \text { A } & \text { G } \\ \text { L } & \text { T } & \text { L } & \text { L } & \text { T } & \text { L } \\ \text { Y } & \text { E } & \text { Y } & \text { Y } & \text { E } & \text { Y } \\ & \text { L } & & & \text { L } & \\ & \text { Y } & & & \text { Y } & \end{array}$

24. The current focus on health promotion is a fad that will probably disappear.

$$
\begin{array}{llllll}
1 & 2 & 3 & 4 & 5 & 6
\end{array}
$$

25. No matter how hard I work to promote health for society, it never seems to $\begin{array}{lllllll}\text { improve. } & 1 & 2 & 3 & 4 & 5 & 6\end{array}$

26. Our society holds no worthwhile goals or values about health.

$$
\begin{array}{llllll}
1 & 2 & 3 & 4 & 5 & 6
\end{array}
$$

27. If I take the right actions, I can stay healthy.

$$
\begin{array}{llllll}
1 & 2 & 3 & 4 & 5 & 6
\end{array}
$$

28. I get excited about the possibility of improving my health.

$$
\begin{array}{llllll}
1 & 2 & 3 & 4 & 5 & 6
\end{array}
$$

29. I am determined to be as healthy as I can be.

$\begin{array}{llllll}1 & 2 & 3 & 4 & 5 & 6\end{array}$

30. When my health is threatened, I view it as a challenge that must be overcome.

$$
\begin{array}{llllll}
1 & 2 & 3 & 4 & 5 & 6
\end{array}
$$

31. I read everything I can about health.

$$
\begin{array}{llllll}
1 & 2 & 3 & 4 & 5 & 6
\end{array}
$$

32. I can be as healthy as I want to be.

$$
\begin{array}{llllll}
1 & 2 & 3 & 4 & 5 & 6
\end{array}
$$

33. When something goes wrong with my health, I do everything I can to get at the root of the problem.

$\begin{array}{llllll}1 & 2 & 3 & 4 & 5 & 6\end{array}$




$\begin{array}{llllll}\text { S } & \text { M } & \text { S } & \text { S } & \text { M } & \text { S } \\ \text { T } & \text { O } & \text { L } & \text { L } & \text { O } & \text { T } \\ \text { R } & \text { D } & \text { I } & \text { I } & \text { D } & \text { R } \\ \text { O } & \text { E } & \text { G } & \text { G } & \text { E } & \text { O } \\ \text { N } & \text { R } & \text { H } & \text { H } & \text { R } & \text { N } \\ \text { G } & \text { A } & \text { T } & \text { T } & \text { A } & \text { G } \\ \text { L } & \text { T } & \text { L } & \text { L } & \text { T } & \text { L } \\ \text { Y } & \text { E } & \text { Y } & \text { Y } & \text { E } & \text { Y } \\ & \text { L } & & & \text { L } & \\ & \text { Y } & & & \text { Y } & \end{array}$

34. I have little influence over my health.

$\begin{array}{lll}4 & 5 & 6\end{array}$

Copyright, 1990, Susan E. Pollock, Ph.D. 


\section{DEMOGRAPHIC DATA}

Please place an $\mathrm{X}$ in the appropriate box.

Gender:

1. Male

2. Female

[ ]

[ ]

Marital Status:

1. Single

2. Married

3. Divorced

[ ]

[ ]

[ ]

Ethnicity:

1. White American

[ ]

2. Black American

[ ]

3. Hispanic American

[ ]

4. Other

Social Support:

1. Family

2. Friends

[ ]

3. Alone

[]

Employment

$\begin{array}{lll}\text { 1. } & \text { Full time } & \text { [ ] } \\ \text { 2. } & \text { Part time } & \text { [ ] } \\ \text { 3. } & \text { None } & \text { [ ] }\end{array}$

Thank you for answering the above questions. 


\title{
GRADUATE STUDIES BULLETIN \\ ANNOUNCEMENT
}

\section{Florida International University \\ Division of Graduate Studies \\ Master's Thesis Defense}

\begin{abstract}
The HARDINESS of adult survivors of child sexual abuse and their adaptation to a healthy adult life style

by

Myra Power Buttacavoli
\end{abstract}

There are many negative consequences of childhood sexual abuse, (Browne \& Kinkelhor, 1990). These conditions do not vanish with adulthood and some adults stay scarred for life. However, it has been noted that some victims of childhood sexual abuse recover better than others regardless of the particular type of abuse. Could this adaptation be related to "hardiness" of the adult?

The purpose of this report is to explore the hardiness of adult victims of child sexual abuse and the adaptation strategies practiced. To achieve this goal, The Health Related Hardiness Scale, created by Susan Pollock, PhD. was adopted. Data was collected from fifteen adult females who, by their own definition were sexually abused as children. They completed the HRHS questionnaire and a demographic questionnaire. Data analysis revealed a significant $p$-value of 0.0002 indicating that support is the most important component to "buffer" the negative effects of stress. However this study revealed a high level of hardiness overall in the participating individuals

Date: November 16, 1995

Department: Nursing

Time: 10:00 a.m.

Place: Miami Children's Hospital, Nursing Office

Major Professor: Dr. Janice Hayes 